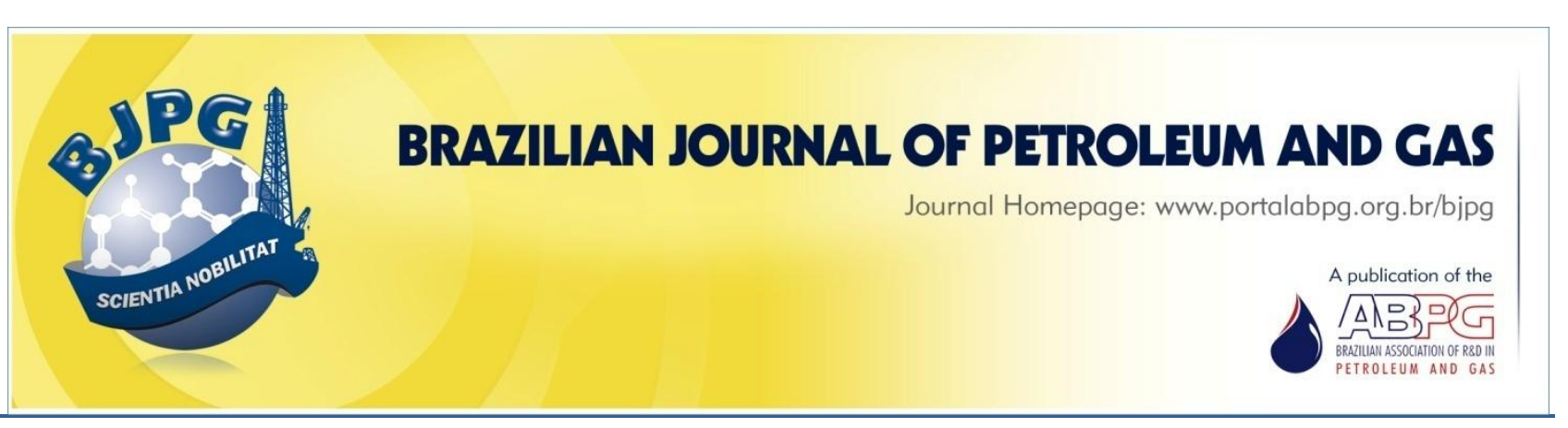

\title{
THE USE OF FACTORIAL DESIGN TO EVALUATE SYSTEMATIC CHANGES IN THE OPERATING CONDITIONS OF A THREE-PHASE SEPARATOR USING SIMULATION AS A TOOL
}

\author{
${ }^{\text {a }}$ Araújo, C. M. B. ${ }^{1}$; ${ }^{\text {a }}$ Nascimento, H. A.; ${ }^{\text {a }}$ Cavalcanti, C. J.; ${ }^{a}$ Sobrinho, M. A. M.; ${ }^{a}$ Pimentel, M. F. \\ ${ }^{a}$ Federal University of Pernambuco, Department of Chemical Engineering, Recife-PE, Brazil
}

Received: 15.08.2017 / Revised: 01.03.2018 / Accepted: 01.03.2018 / Published on line: 16.04.2018

\begin{abstract}
This work aims to use factorial designs to evaluate changes in the operating conditions of a three-phase separator. It performs experiments using a Hysys simulation software. It evaluates the influences of temperature, working pressure, and type of separator for light and heavy oils. To find the best operating conditions theoretically, higher oil flow rate (outlet stream) and smaller amount of water in the oil stream are used as reference goals. After performing simulations, the data is analyzed, and one can observe that the effect type of separator does not have a statistically significant influence in the results. The best operating condition occurs with the temperature at $30^{\circ} \mathrm{C}$ and the pressure at 9 bar, lowest and highest levels suited, respectively.
\end{abstract}

\section{KEYWORDS}

factorial design; operating conditions; simulation; three-phase separator

\footnotetext{
${ }^{1}$ To whom all correspondence should be addressed.

Address: UFPE, Departamento de Engenharia Química, Ave. Prof. Moraes Rego, 1235, Cidade Universitária, Recife - PE, Brasil. ZIP Code: 50670-901 | e-mail: carolinemariaba@gmail.com doi:10.5419/bjpg2018-0002
} 


\section{INTRODUCTION}

Oil production is accompanied usually by the joint production of water and gas. During the course to the surface, due to severe pressure and temperature conditions, the mixing between the three phases occurs (Santos, 2013). Thus, oilwater-gas separation must be one of the first operations to be carried out after crude oil extraction. After the extraction process, the mixing goes to a primary processing stage, which aims to separate the three phases (Vileiniskis et al., 2016).

Three Phase Separator (TPS) is a large vessel used to separate petroleum-produced fluids into gas, oil, water, and solid impurities. The separation vessel is the initial processing equipment which has a great influence in the entire plant's capacity. An inappropriate design of a three-phase separator can lead to problems, reducing equipment efficiency. Thus, a TPS failure can make the entire oil processing plant stop (Ghaffarkhah et al., 2017). TPS operation is based on gravity force, so the fluid with a higher density will settle on the bottom of the separator, and the fluid with lower density will flow to the top of the separator. Different types of separators can be used, being the most common ones horizontal, vertical and spherical separators (Vileiniskis et al., 2016).

Water separation is the most complex and important stage of the primary processing, since its presence in the oil stream can increase corrosion and hydrates formation (Dantas et al., 2012). The water can occur in the oil stream in its free form or as a water-oil emulsion, which is quite undesirable, since the stability of water-in-oil emulsions is a major problem in primary separation (Santos, 2013). In offshore platforms, for example, emulsions formation can also be influenced by external factors such as amplitude of waves, sea currents, and winds that provoke movements in both horizontal and vertical planes (Martins, 2017).

On the other hand, the flow rate of produced water after the primary processing also requires adequate treatment so that it can be properly disposed and/or reinjected into the wells (Dantas et al., 2012; Seureau et al., 1994). Since several oil wells, especially the older ones, are becoming less economical due to high production costs and reduced recovery, the study of variables influencing the oil-water separation process, points to the best operating conditions, and aims at increasing efficiency. Such studies may lead to an improvement in the oil recovery process, in addition to the reduction of environmental impacts (Zeng et al., 2016).

For sizing a TPS it is necessary to choose the vessel's shape, length and diameter, as these can also influence the separation process. In the semiempirical method, vessel dimensions are calculated to allow the phases reaching equilibrium. Although some useful design considerations can be provided by this approach, very important information, which may affect the separator performance, are usually disregarded (Ghaffarkhah et al., 2017).

This work aims to use factorial designs to evaluate changes in the operating conditions of a three-phase separator, performing the experiments using Hysys as the simulation software. The influences of temperature, working pressure, and type of separator for lighter and heavier oils were evaluated through the accomplishment of two factorial designs $2^{3}$, to find, in theory, the best operating conditions. The objective here was to obtain the highest oil flow rate in the product stream, as well as the smallest percentage of water in the oil stream. This would increase process efficiency as a whole. Also, according to the factorial design results, a comparative study was proposed between heavier and lighter oils, of how the 2 responses change when the temperature ranges from 30 to $50{ }^{\circ} \mathrm{C}$ for a fixed pressure value ( 9 bar).

\section{MATERIALS AND METHODS}

The TPS simulation was performed using Aspen Hysys $^{\circledR} 8.8$ software, in stationary mode. To proceed with the separation, the software performs a $\mathrm{P}-\mathrm{H}$ flash to determine the products conditions and phases. The pressure at which the flash is performed is the lowest feed pressure minus the pressure drop across the vessel. The enthalpy is the combined feed enthalpy plus or minus the duty. Thus, for heating, the duty is added; as for cooling, the duty is subtracted (Clement \& Smith, 2003).

The thermodynamic model chosen to proceed with the simulations was Peng-Robinson. In this regard, it is worth mentioning that Hysys contains 


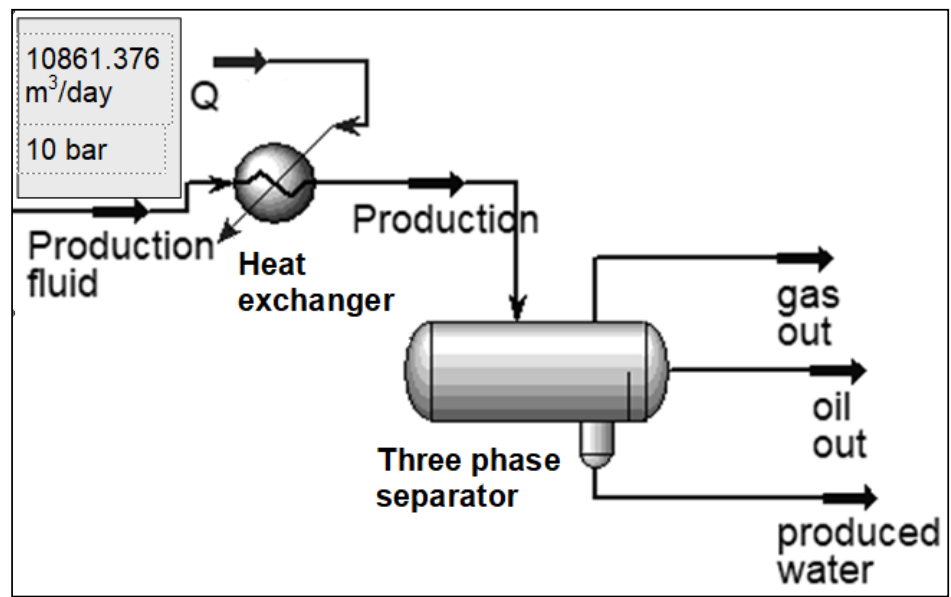

Figure 1. Process flow diagram for the TPS used during the experiments.

more than 35 mathematical models for liquidvapor equilibrium, liquid-liquid, and enthalpy calculation (West et al., 2008). Other models such as UNIQUAC, NRTL, and Extended NRTL were tested for the studied system. However, in these cases the Peng-Robinson Equation of State (EOS) was deemed more appropriate, since it was the one that best suited the proposed system, under the studied conditions (Jahangiri \& Nouri, 2014).

Cubic EOS has been used widely to model the oil and gas phases in phase equilibrium calculations. Thus, several attempts have been made to model the aqueous phase using the same EOS (Li \& Nghiem, 1986). A cubic EOS was chosen because in process design, it allows fast screening of a great number of design alternatives, due to its low complexity and high accuracy for many compounds in non ideal conditions. In this case also, the use of an EOS was necessary since there are two liquid phases coexisting - i.e., the liquid phase was not ideal either (Jaubert et al., 2010).

As an example, Jahangiri and Nouri (2014) used Hysys, applying the Peng-Robinson EOS to simulate a TPS system. In that case, they observed that by comparing the data obtained experimentally and the data from the simulation program, all the parameters, such as temperature, working pressure, and flow rates were in general very close together or only slightly different between them.

In the present work, during the simulation, two different systems were evaluated, differing only in the composition of the oil phase in the inlet stream. Thus, in the first situation, only the presence of a "lighter oil" (C2 - C10) was considered in the inlet stream; as in the second situation, the oil fraction in the production stream was assumed to be composed of "heavier oil" (C11 - C20). The compositions were given according to the data provided by Akpan (2013).

In this case, the variable "type of oil" was excluded, regarding the oil composition in the factorial design planning. Instead, two factorial designs were made, since the type of oil is something already predetermined before doing the design of the vessel, being clearly relevant and therefore significant for the whole process.

Figure 1 shows the process flow diagram of the three-phase separation process. In this case, it was assumed that the system was fed with a total volumetric flow rate of $10861.376 \mathrm{~m}^{3} /$ day (production stream), and that the volume of water, oil, and gas in the inlet stream was the same (Mendonça et al., 2013). The volume of the vessel was assumed to be equal to $1 \mathrm{~m}^{3}$, similar to the one used in the Potiguar Basin Fluid Processing and Treatment Unit - UTPF (Mendonça et al., 2013), and the inlet pressure of the fluid entering the separator was 10 bar, as some cases in literature reported inlet pressures entering the vessel near this value (Akpan, 2013; Jahangiri, Nouri, 2014).

The temperature of the fluid entering the TPS was varying according to the factorial design. The temperature range used was also in accordance to previous works (Jahangiri \& Nouri, 2014; Universidade Petrobras, 2007). 
Table $1.2^{3}$ factorial design variables and levels.

\begin{tabular}{lcc}
\hline \multicolumn{1}{c}{ Variables } & $(-)$ & $(+)$ \\
\hline (1) Temperature, ${ }^{\circ} \mathrm{C}$ & 30 & 50 \\
(2) Type of separator & Vertical & Horizontal \\
(3) Working pressure, bar & 6 & 9 \\
\hline
\end{tabular}

To evaluate the efficiency of water-oil separation inside the vessel, two complete factorial designs $2^{3}$ (one for lighter and another one for heavier oil) were carried out. The studied variables were: temperature (1), type of separator (2), and working pressure (3) (Erwin, 2016). The levels of these variables can be seen in Table 1.

The working pressure values shown in Table 1 were chosen based on the most common operation values for a TPS (Universidade Petrobras, 2007). The TPS vessel used was in a Flat Cylinder shape, which is available in Hysys for either horizontal or vertical vessels. If only the total cylindrical volume of the vessel is specified, the height to diameter ratio is defaulted by the software as 3:2 (Clement \& Smith, 2003). Thus, the total volume of the vessel equals to $1 \mathrm{~m}^{3}$ was used.

According to Clement and Smith (2003), in Hysys, the main difference between vertical and horizontal cylindrical TPS is that the liquid height in a vertical vessel changes linearly with the liquid volume; on the other hand, for the horizontal (as well as the spherical) vessels, there is a nonlinear relationship between the liquid height and the liquid volume. Thus, even in stationary mode, there will be a difference in the separation process if one uses the cylindrical vessel in one orientation or another.

Data analysis was performed taking into account the type of oil in the inlet stream, regarding two output responses: oil flow rate in the outlet stream $\left(\mathrm{m}^{3} / \mathrm{h}\right)$, and mass percentage of water in the oil stream (\%). This evaluation was carried out using a Statistica Utimate Academic ${ }^{\circledR}$ software. The mass percentage of water in the oil stream was obtained dividing the mass flow rate of water in the oil outlet stream by the overall mass flow rate in the stream, multiplying the results by $100 \%$. In Hysys, TPS can use the known feed composition to determine the product streams compositions (Clement \& Smith, 2003).
After carrying out the factorial design experiments and their corresponding analysis, it was also proposed a comparative study, between heavy and the light oils, of how the 2 responses studied behave when the temperature ranges from 30 to $50{ }^{\circ} \mathrm{C}$. In this case, the pressure was fixed at 9 bar. The data collected for this comparative study was also obtained by means of simulation, using Hysys.

\section{RESULTS AND DISCUSSIONS}

The results obtained during the experiments, for both responses, are given in Tables 2 and 3, according to the type of oil studied.

The analysis of the results might be done based on the normal probability plots, given by Figures 2 , 3,4 , and 5 . In this case, the normal graphs will be used since the experiments were performed using a simulation software, in which it is not necessary to perform the tests in duplicate. In general, for the normal plots, the positive values of the effects mean that an increase in their levels leads to an increase in the oil flow rate or in the \% of water in the oil stream. On the other hand, the negative values of the effects lead to a reduction of the percentage removal when their levels are increased.

Initially, from an overall analysis of the four normal graphs, one can see that the main effect type of separator, as well as the interaction effects of two and three factors, do not present statistical significance at $95 \%$ confidence, since the values were all very close to zero. Thus, these effects, in some cases, also ended up being superimposed on the graphs (Barros Neto et al., 1996; Rathinam et al., 2011). These results were already expected, since they assumed the volumetric flow rates of water, oil, and gas to be equal. Vertical separators are used normally when the gas-liquid ratio is high. 
Table 2. Factorial design matrix with the responses to the lighter oil.

\begin{tabular}{cccccc}
\hline \multicolumn{3}{c}{ Variables } & & Volumetric flow rate of Oil - \\
Experiment & 1 & 2 & 3 & outlet stream $\left(\mathrm{m}^{3} / \mathrm{h}\right)$ & $\begin{array}{c}\text { Mass percentage of water in the } \\
\text { oil stream (\%) }\end{array}$ \\
\hline 1 & - & - & - & 248.3 & 0.0099 \\
2 & + & - & - & 216.5 & 0.022 \\
3 & - & + & - & 248.3 & 0.0099 \\
4 & + & + & - & 216.5 & 0.022 \\
5 & - & - & + & 263.5 & 0.011 \\
6 & + & - & + & 232.8 & 0.025 \\
7 & - & + & + & 263.5 & 0.011 \\
8 & + & + & + & 232.8 & 0.025 \\
\hline
\end{tabular}

Table 3. Factorial design matrix with the responses to the heavier oil.

\begin{tabular}{cccccc}
\hline \multicolumn{3}{c}{ Variables } & & Volumetric flow rate of Oil - outlet \\
Experiment & 1 & 2 & 3 & stream $\left(\mathrm{m}^{3} / \mathrm{h}\right)$ & $\begin{array}{c}\text { Mass percentage of water in } \\
\text { the oil stream }(\%)\end{array}$ \\
\hline 1 & - & - & - & 402.9 & 0.0045 \\
2 & + & - & - & 402.6 & 0.011 \\
3 & - & + & - & 402.9 & 0.0045 \\
4 & + & + & - & 402.6 & 0.011 \\
5 & - & - & + & 404.0 & 0.0046 \\
6 & + & - & + & 403.6 & 0.011 \\
7 & - & + & + & 404.0 & 0.0046 \\
8 & + & + & + & 403.6 & 0.011 \\
\hline
\end{tabular}

On the other hand, horizontal separators are used generally for high overall liquid volumes. This study assumed that the amount of liquid does not differ much from the amount of gas. Therefore, the effect type of the separator, in fact, should not be significant in this case.

\subsection{0il flow rate}

According to Tables 2 and 3, within the studied range, the highest oil flow rate in the outlet stream is $263.5 \mathrm{~m} \mathrm{~m}^{3} / \mathrm{h}$ for the lighter oil and $404.0 \mathrm{~m}^{3} / \mathrm{h}$ for the heavier oil. In both cases, these results were obtained with the temperature at the lowest level $\left(30^{\circ} \mathrm{C}\right)$ and the working pressure at its upper level (9 bar).

By analyzing the normal probability plots in Figures 2 and 3, it is possible to see that only the main effects temperature and working pressure are significant for both the lighter and the heavier oil. In this case, it is observed that, in fact, the temperature influences negatively the process. The best operating condition, when the highest oil flow rate is obtained at the outlet stream, would be with temperature at its lower level. This could be justified by the fact that the higher the temperature, the more components in the "oil phase" would pass into the "vapour phase," going directly into the gas stream (Sayda \& Taylor, 2007).

In regards to the effect of working pressure, it influences the process in a positive way. The best operating condition, when the highest oil flow rate is obtained, may occur when the working pressure is at its highest level. It should be noticed, though, that a higher working pressure in this case, indicates a lower pressure drop inside the vessel, which would generate less turbulence inside the separator, facilitating the separation process by gravity.

Although by default the HYSYS separators are ideal separators, in practice, when operating a real vessel, this could, to a certain extent, decrease the chance to form emulsions within the separator, which would contribute to explain even more the fact that the separation occurs more efficiently when the working pressure is kept closer to the inlet pressure (Clement \& Smith, 2003). 


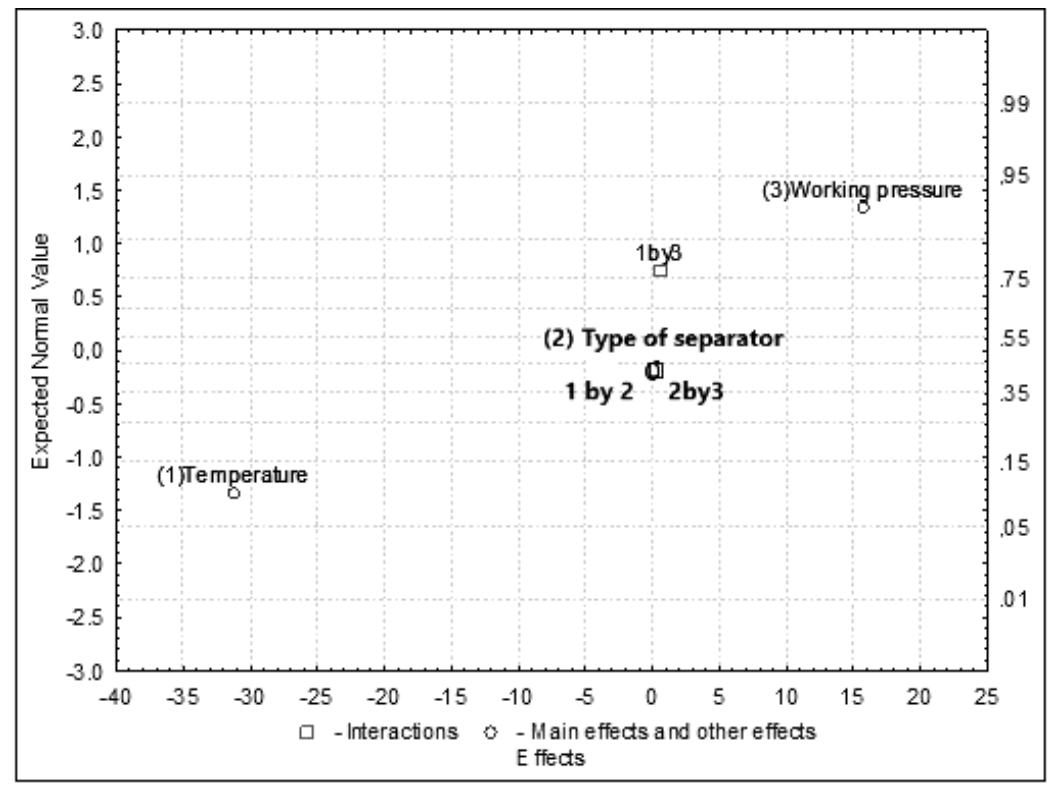

Figure 2. Normal probability plot for the volumetric flow rate of lighter oil at the outlet stream.

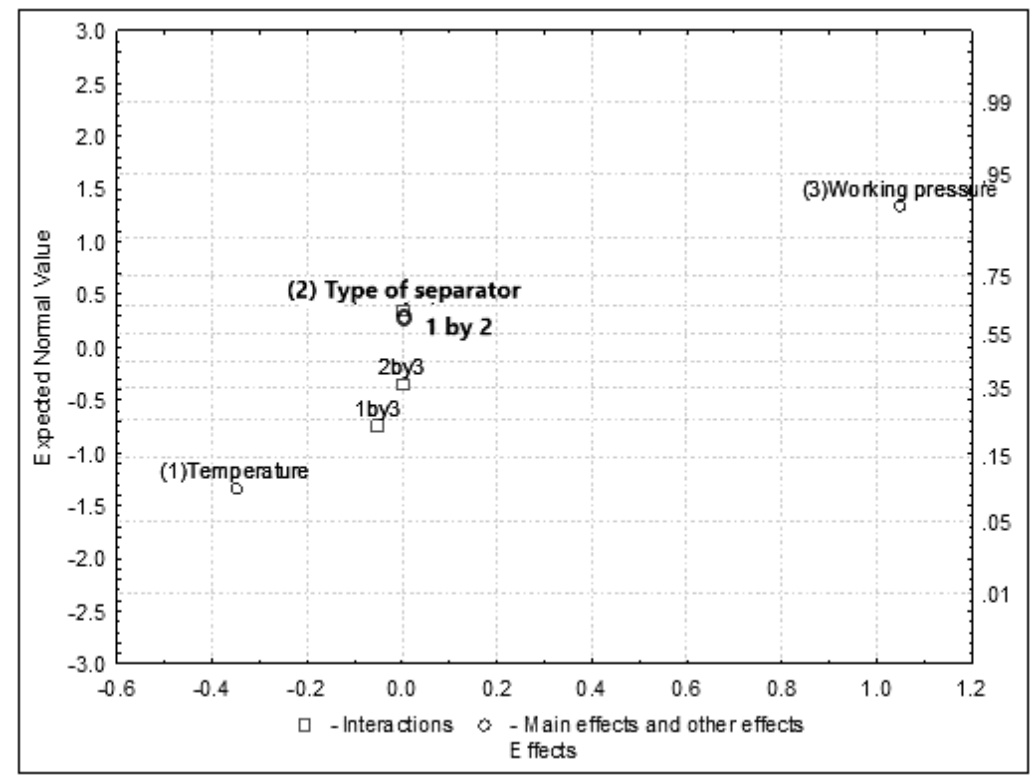

Figure 3. Normal probability plot for the volumetric flow rate of heavier oil at the outlet stream.

Martins (2017) studied the performance of a three-phase separator regarding the effects of sea wave motion. In that work, three phase separator performance was defined by the emulsions quality indicator, which is based on the amount of free water which exceeds the dam at the final section of the separator. One could observe that an offshore separator strongly dependent on the platform movements (i.e., on the external forces acting on the separator). The combination of these parameters directly influences emulsions quality.

Although in the present work external forces acting on the vessel were not studied, the turbulence caused by a larger pressure drop (for lower input pressure values) may, in fact, have similar effects on the system to that observed in Martins (2017) work. That could influence directly the formation and quality of water-oil emulsions obtained. 


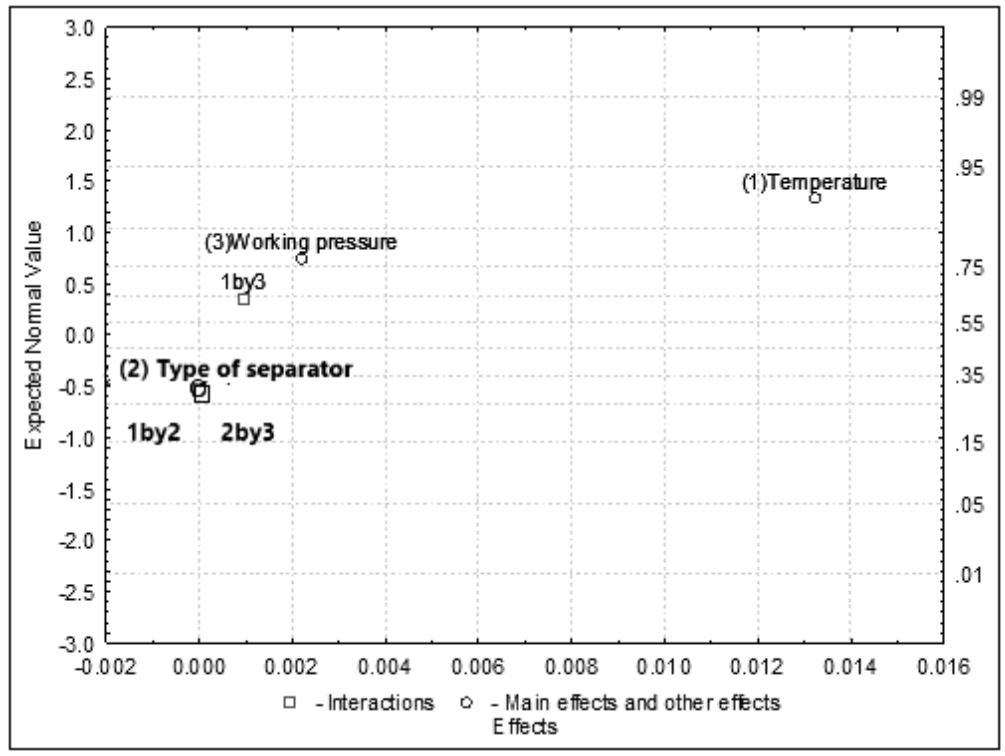

Figure 4. Normal probability plot for the percentage of water in the outlet stream for the lighter oil.

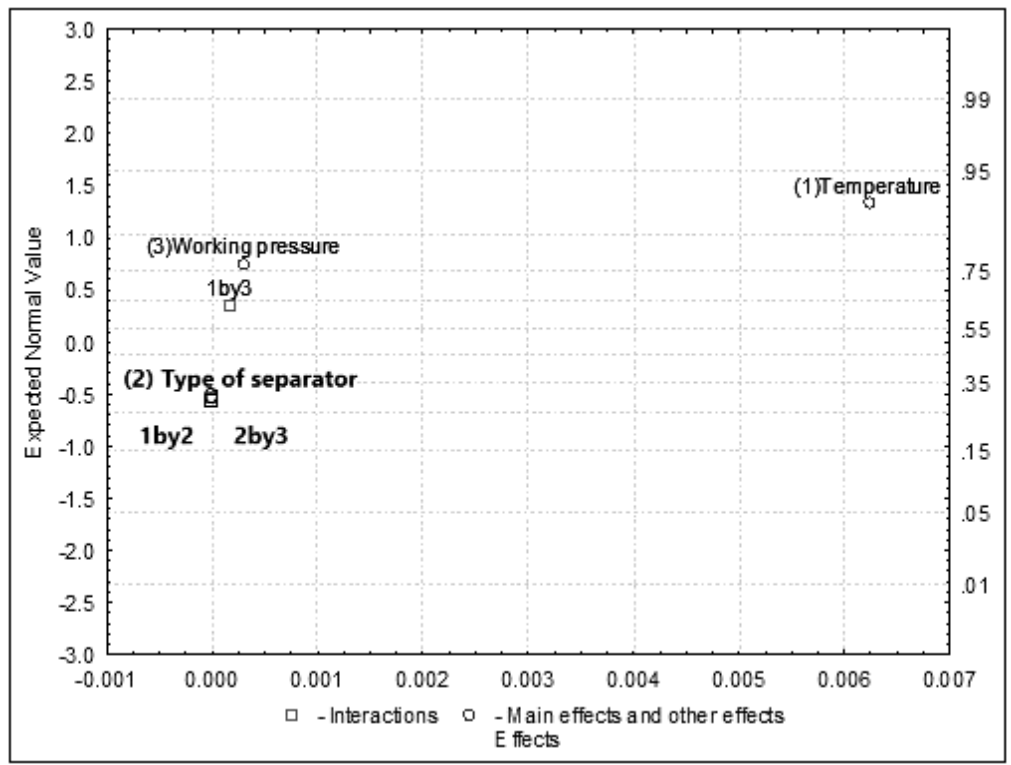

Figure 5. Normal probability plot for the percentage of water in the outlet stream for the heavier oil.

\subsection{Mass percentage of water in the oil outlet stream}

As Hysys gives the compositions of all product streams in the TPS, it was possible to calculate the percentage of water in the oil outlet stream. Initially, according to the results in Tables 2 and 3, it is observed that within the studied range, the lowest percentage of water in the oil stream corresponds to $0.0099 \%$ for the lighter oil and $0.0045 \%$ for the heavier oil. In both cases, these results are obtained with temperature and working pressure at their lowest levels.

However, for both the lighter and the heavier oil, it is possible to notice from the analysis of the normal probability plots, given by Figures 4 and 5 , that only the main effect temperature is significant, since all the other effects (including the effect of working pressure) could not be considered statistically significant at a $95 \%$ confidence level. 


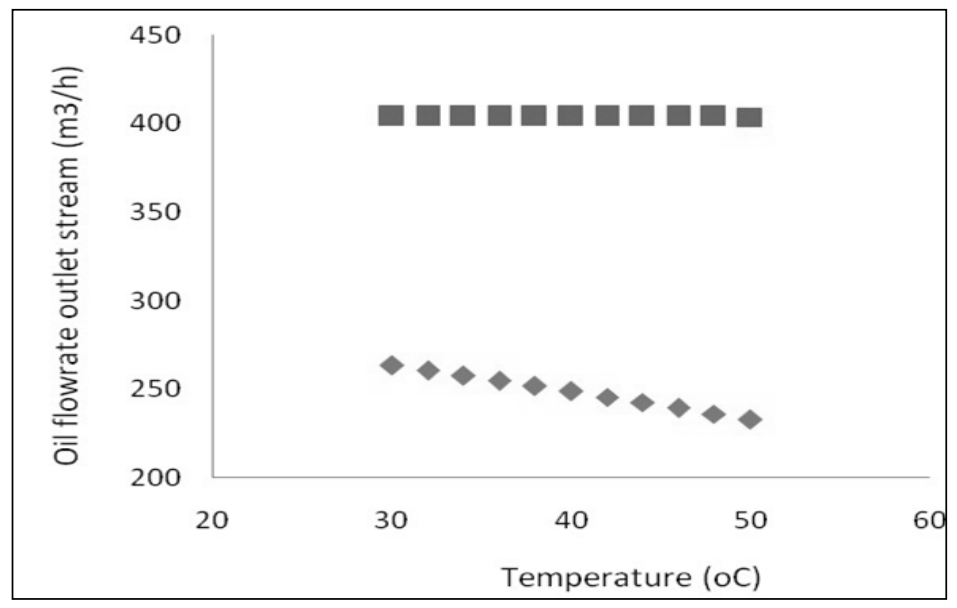

Figure 6. Temperature vs. volumetric flow rate of oil in the outlet stream for both the lighter $(\bullet)$ and the heavier ( $\mathbf{a})$ oil.

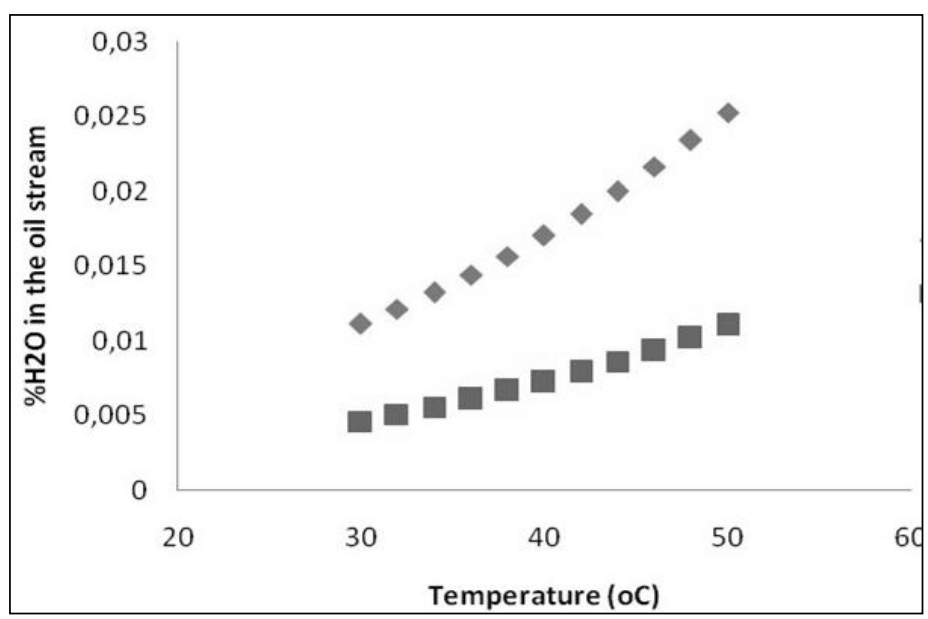

Figure 7. Temperature vs. mass percentage of water in the oil stream for both the lighter $(\bullet)$ and the heavier ( $\mathbf{a})$ oil.

In this case, one can observe that temperature influences positively the process. The higher the temperature, the higher the percentage of water in the oil outlet stream is. Thus, the best operating condition, which is when the lowest percentage of water in the oil outlet stream is obtained, occurs with the temperature at its lowest level. This could be explained by the fact that the higher the temperature, the greater the formation of water vapours is. That then ends up going to the lighter (upper) current, which in this case is the oil stream (Sayda \& Taylor, 2007).

In fact, according to Paasimaa (2005), the dependence of water-oil solubility on temperature is generally exponential. Thus, the hotter the oil is, the greater the amounts of water it dissolves.

\subsection{Comparative analysis for temperature changes}

According to the experimental design analysis, as the temperature effect was statistically significant for both responses studied, the graphs showing how the responses are affected by the changes in temperature were then made, as one can see in Figures 6 and 7.

By analyzing Figure 6, one can see that the effect of increasing the temperature in the oil flow rate is more pronounced in the lighter than in the heavier oil system. For the lighter oil, it is possible to notice more clearly that as the temperature increases, a reduction in the oil flow rate occurs at the exit of the separator. On the other hand, for the heavier oil, the oil flow rate in the outlet 
stream remains practically steady during the process.

As it was previously explained in section 3.1, the higher the temperature is, the more components in the "oil phase" will pass into the "vapour phase," going directly into the gas stream. That would, then, end up reducing the oil flow rate. However, as the lighter oil has a greater number of smaller hydrocarbon molecules, more components in the oil phase will pass into the gas phase when increasing the temperature, compared to the heavier oil, reducing the oil flow rate in the outlet stream more significantly as well.

By analyzing Figure 7 , it is possible to notice that, again, the temperature effect in the mass percentage of water in the oil stream is more prominent in the lighter oil than in the heavier oil. As mentioned previously, the dependence of water-oil solubility on temperature is generally exponential (see the shape of the curves). The hotter the oil is, the greater the quantity of water that can be dissolved will be (Paasimaa, 2005). As the increase in temperature also favors the lighter hydrocarbons to go to the gas phase, there will be even more water and less oil in the oil stream for the lighter oil system, than for the heavier oil system, when the pressure is kept constant at 9 bar.

According to Erwin (2016), the water separation process may as good as $90 \%$, or even less than $50 \%$, depending on the difference between the relative densities of the oil and the water. Thus, in fact, the density of the oil plays an important role in the water-oil separation process.

\section{CONCLUSIONS}

In this study, the authors found that the effect "type of separator" is not statistically significant in any of the proposed systems; although the effect "temperature" is quite significant for both responses considered. Regarding the effect of "working pressure," one could observe that it was significant only for the oil flow rate response. In general, it was verified that the best operating condition for the proposed system, within the studied range, occurs when the temperature is at its lowest level $\left(30{ }^{\circ} \mathrm{C}\right)$ and the pressure is at its highest level (9 bar). By analysing how the responses change with temperature, it was possible to notice that, for both responses considered, the effect of increasing the temperature generally is more pronounced in lighter oil than in heavier oil, under the studied conditions.

In future studies, the authors propose a comparison between simulation data with real data to completely validate the results and effects discussed in the present work. They also suggest to repeat this preliminary study using other thermodynamic packages (i.e., more adequate cubic EOS) to compare the data, as well as to analyse how that would affect the system and the responses.

\section{ACKNOWLEDGEMENTS}

To the Graduate Program in Chemical Engineering (PPGEQ) at the Federal University of Pernambuco (UFPE) and the Department of Chemical Engineering (DEQ) of UFPE.

\section{REFERENCES}

Akpan, D. G. Performance of internals in threephase tank separators. MSc Thesis. Trondheim, Norwegian University of Science and Technology, p. 177, 2013.

Barros Neto, B.; Scarminio, I. S.; Bruns, R. E. Planejamento e otimização de experimentos. Campinas: UNICAMP, 1996.

Clement, N.; Smith, P. Hysys 3.2 User Guide. Hyprotech, a subsidiary of Aspen Technology Inc, 2003. Available at: http://yunus.hacettepe.edu.tr/ ealper/kmu346/tu torial/OpsGuide.pdf. Accessed on: 25 October 2017.

Dantas, A. F. A.; Linhares, L. L. S.; Pinto, J. E. M. G.; Araujo, F. M. U.; Maitelli, A. L. Evaluation and optimization of three phase separator vessel controlled by PI controls applying particle swarm optimization. 10th Portuguese Conference on Automatic Control, Portugal, 2012.

Erwin, D. L. Industrial Chemical Process Design. 2nd Edition. USA: Bookman, 2016. 
Ghaffarkhah, A.; Shahrabi, M. A.; Moraveji, M. K.; Eslamini, H. Application of CFD for designing conventional three phase oilfield separator. Egyptian journal of petroleum, v. 26, n. 2, p. 413420, 2017.

Jahangiri, M. R.; Nouri, M. Simulation of threephase separator in petroleum industry. Journal of Chemical and Pharmaceutical Research, v. 6, n. 11, p. 923-936, 2014.

Jaubert, J.; Privat, R.; Mutelet, F. Predicting the phase equilibria of synthetic petroleum fluids with the PPR78 approach. AIChE journal, v. 56, n. 12, p. 3225-3235, 2010. https://doi.org/10.1002/aic.12232

Li, Y.-K.; Nghiem, L. X. Phase equilibria of oil, gas and water/brine mixtures from a cubic equation of state and Henry's law. The Canadian Journal of Chemical Engineering, v. 64, n. 3, p. 486-496, 1986. https://doi.org/10.1002/cjce.5450640319

Martins, C. F. Estudo do desempenho de um separador trifásico devido aos efeitos dos movimentos de uma FPSO sob ação de ondas do mar. MSc Thesis. Campinas, Universidade Estadual de Campinas, 2017.

Mendonça, É. T. R.; Ferreira, J. M.; Motta Sobrinho, M. A. Tratamento da água de produção de petróleo através de processos combinados. Revista AIDIS de Ingeniería y Ciencias Ambientales: investigación, desarrollo y práctica, v. 6, p. 89-99, 2013.

Paasimaa, S. Factors affecting water solubility in oils. Vaisala News, v. 169, p. 24-25, 2005.

Rathinam, A.; Rao, J. R.; Nair, B. U. Adsorption of phenol onto activated carbon from seaweed: Determination of the optimal experimental parameters using factorial design. Journal of the Taiwan Institute of Chemical Engineers, v. 42, n. 6, p. 952-956, 2011.

https://doi.org/10.1016/i.jtice.2011.04.003

Santos, W. L. Tecnologia de micro-ondas aplicada a desestabilização de emulsões de petróleo. XXXIII Encontro Nacional de Engenharia de Produção, Salvador, 2013. Available al: http://docplayer.com.br/12058147-Teconologiade-micro-ondas-aplicada-a-desestabilizacao-deemulsoes-de-petroleo.html. Accessed on: 21 October 2017.
Sayda, A. F.; Taylor, J. H. Modeling and control of three-phase gravilty separators in oil production facilities. American Control Conference, 2007. p. 4847-4853. Available in:

<http://ieeexplore.ieee.org/document/4282265/?p art=1>. Accessed on: 21 Oct 2017.

Seureau, J. J.; Aurelle, Y.; Hoyack, M. E. A threephase separator for the removal of oil and solids from produced water. SPE Annual Technical Conference and Exhibition. Society of Petroleum Engineers, 1994. Available at:

<https://www.onepetro.org/conferencepaper/SPE-28535-MS>. Accessed on: 22 October 2017.

Universidade Petrobras - Escola de Ciências e Tecnologias E\&P. Processamento Primário de Petróleo. Rosana Kunert Editor. Rio de Janeiro, 2007.

West, A. H., Posarac, D., Ellis, N. Assessment of four biodiesel production processes using HYSYS. Plant. Bioresource Technology, v. 99, p. 65876601, 2008.

https://doi.org/10.1016/j.biortech.2007.11.046

Vileiniskis, M.; Remenyte-Prescott, R.; Rama, D.; Andrews, J. Fault detection and diagnostics of a three-phaseseparator. Journal of Loss Prevention in the Process Industries, v. 41, p. 215-230, 2016. https://doi.org/10.1016/j.jlp.2016.03.021

Zeng, Q.; Wang, Z.; Wang, X.; Zhao, Y.; Guo, X. A novel oil-water separator design and its performance prediction. Journal of Petroleum Science and Engineering, v. 145, p. 83-94, 2016. https://doi.org/10.1016/i.petrol.2016.03.015 